\title{
Assessment of Knowledge and Awareness Regarding the Postmenopausal Syndrome in Women Aged above 30 Years in Quetta, Pakistan
}

\author{
Aqeel Nasim ${ }^{1}$, Noman U Haq ${ }^{2}$, Sohail Riaz ${ }^{3}$, Gul Khanda ${ }^{4}$, Muhammad S Zarak ${ }^{5}$, Maria Tahir ${ }^{6}$, Muhammad Saood $^{7}$, \\ Yasmin $\mathrm{Shah}^{8}$
}

\begin{abstract}
Background: More awareness regarding the postmenopausal syndrome (PMS) is needed for women to leading a quality life. Postmenopausal symptoms adversely affect the life expectancy and quality of life (QoL) of women. The aim of this study was to determine the knowledge and awareness regarding the postmenopausal syndrome among women above 30 years in Quetta, Pakistan. This study was to assess the amount of knowledge women have about postmenopause, its causes, symptoms, diagnosis, treatment, and complications.

Materials and methods: A cross-sectional, interview-based survey was conducted from January to September 2016 . An estimated 447 women (aged above 30 years) were selected. Their knowledge about the postmenopausal syndrome was assessed by a structured questionnaire. A convenient sampling technique was used to collect data.

Results: A total of 550 questionnaires were distributed, of which 447 were returned (response rate: $81 \%$ ). The mean age of the respondents was $38.06 \pm 6.194$ years. The mean of the total knowledge score was $12.77 \pm 3.910$. Totally, $53.0 \%$ had adequate knowledge regarding the postmenopausal syndrome and $47.0 \%$ had a poor knowledge regarding the postmenopausal syndrome.A total of $73.5 \%$ of the respondents were aware of the age of menopause. Majority of the respondents know the causes of the postmenopausal syndrome. An estimated 45.3\% knew that it can be diagnosed by a blood test. A total of $43.8 \%$ did not know about the hormone replacement therapy used for the treatment of the postmenopausal syndrome.

Conclusion: The purpose of this study was to assess the knowledge among Quetta women regarding the postmenopausal syndrome, its causes, symptoms, diagnosis, treatment, and complications. This study found that the knowledge among women regarding the postmenopausal syndrome is important for improving their QoL and for managing the symptoms of the postmenopausal syndrome. The study participants showed an adequate level of knowledge about the postmenopausal syndrome; however, there were areas of knowledge that need improvement by health education. Healthcare professionals should give all the necessary information to women about the postmenopausal syndrome. The ratio of poor knowledge can be improved by raising the awareness and increasing the education level of women.
\end{abstract}

Keywords: Awareness, Knowledge, Postmenopausal syndrome, Symptoms.

Journal of South Asian Federation of Menopause Societies (2019): 10.5005/jp-journals-10032-1164

\section{INTRODUCTION}

Menopause is the end of the menstrual cycle, which leads to stopping the ovarian function and marks an end of the female reproductive cycle. ${ }^{1}$ With increasing global residents in the approaching years, it is assessed that 1.2 billion women globally will be menopausal or postmenopausal by the year 2030. Most common symptoms of menopause are vasomotor symptoms, sleep disturbances, and vaginal dryness. It is roughly calculated that $85 \%$ of women with the postmenopause have knowledge on a menopause-related symptom in their lifetime. The prevalence of VMS alone is found in around 40-50 million women in the United States. ${ }^{2}$

In a study, the prevalence of sleep-related symptoms in 780 postmenopausal women was $40.1 \%$. Another study conducted in Latin America found that the incidence of symptoms related to sleep was $68.4 \%$ and that another study conducted in Malaysia showed that the incidence of sleep-related symptoms was $64.35 \% .{ }^{3}$ In a study conducted in Australia, the prevalence of symptoms related to sleep was $33.7 \%$. In a study conducted in Chandigarh, India, symptoms related to sleep were reported in $36.8 \%$ of women. In another study conducted in Punjab, India, the incidence of sleep disorders was reported to be $53.12 \%$. In a study conducted in Chandigarh, India, the incidence of sleep disorders was recorded as $18.8 \% .^{3}$

\begin{abstract}
$1,2,4,7,8$ Department of Pharmacy, University of Balochistan, Quetta, Balochistan, Pakistan

${ }^{3}$ Department of Pharmacy, Akson College of Pharmacy, Mirpur, Azad Jammu and Kashmir, Pakistan

${ }^{5}$ Department of Medicine, Bolan Medical College, Quetta, Balochistan, Pakistan

${ }^{6}$ Department of Pharmacy, Sardar Bahadur Khan Women's University,
\end{abstract} Quetta, Balochistan, Pakistan

Corresponding Author: Aqeel Nasim, Department of Pharmacy, University of Balochistan, Quetta, Pakistan, Phone: +92 3337879598, e-mail: aqeel_nasim@yahoo.com

How to cite this article: Nasim A, Haq NU, Riaz S, et al. Assessment of Knowledge and Awareness Regarding the Postmenopausal Syndrome in Women Aged above 30 Years in Quetta, Pakistan. J South Asian Feder Menopause Soc 2019;7(1):24-28.

Source of support: Nil

Conflict of interest: None

In England, the normal age of the postmenopausal syndrome is 52 years (National Health Service), while in the United States it is 51 years (National Institute of Aging). Approximately one in five women in India has had menopause before the age of 41 years. ${ }^{4}$

() The Author(s). 2019 Open Access This article is distributed under the terms of the Creative Commons Attribution 4.0 International License (https://creativecommons. org/licenses/by-nc/4.0/), which permits unrestricted use, distribution, and non-commercial reproduction in any medium, provided you give appropriate credit to the original author(s) and the source, provide a link to the Creative Commons license, and indicate if changes were made. The Creative Commons Public Domain Dedication waiver (http://creativecommons.org/publicdomain/zero/1.0/) applies to the data made available in this article, unless otherwise stated. 
But there is no way to estimate when a woman will have menopause or begin to have symptoms. The age at which a woman begins menstruation is not related to the onset of menopause. ${ }^{5}$ Most women have menopause between the ages of 45 and 55, but menopause can occur as early as 30 or 40 years, or it may not occur until a woman turns $60 . .^{5}$

With life expectancy on the rise throughout the world, most women will experience menopause. Therefore, they should have information about the adverse effects of menopause and how to prevent them. In Western countries, women often have good information about the effects of menopause. Cardiovascular problem after menopause. ${ }^{6}$ Women in the eastern communes who lost menopause as a natural process and responded positively showed that $91.7 \%$ of Chinese women in Taiwan observed menopause as a natural process and most of these women are able to cope with menopause in a positive way. Another cross-sectional study based on the population of South India also showed similar results: $57 \%$ of women who had menopause felt comfortable. Among Western studies, a study of 53 Canadian women aged 45-75 years showed similar results that most women handled menopause positively and most considered it a natural aging process. ${ }^{6}$

Knowledge is the ability to achieve, retain, and use information: a combination of understanding, experience, differentiation, and skills. ${ }^{7}$ The nature of knowledge depends on different modes of acquisition: perception, imagination, memory, judgment, summary, and reasoning. ${ }^{7}$

So far, no studies have been reported in Quetta to assess the knowledge of the menopausal syndrome. Therefore, this study aimed to evaluate the knowledge about the menopause syndrome. The evaluation of knowledge can be useful to develop information about the disease.

\section{Materials and Methods}

\section{Study Design, Setting, and Population}

A cross-sectional questionnaire-based study was conducted among a general women population of Quetta, Pakistan. The study was conducted in different areas of Quetta, Pakistan. Women of Quetta, Pakistan were approached for participation in the study, of which 411 women living in different areas of the Quetta city completely filled the criteria. The study was conducted from January to September 2016. The data were collected between the period of 4 months (i.e., April-July 2016).

\section{Study Tool}

A structured questionnaire was used as a research instrument. The questionnaire consisted of closed-ended questions. The questionnaire is designed to assess the knowledge and awareness regarding the postmenopausal syndrome in women above 30 years. The primary version of the questionnaire was developed by previous studies. It consisted of 23 closed-ended questions with the option of YES, NO, and DON'T KNOW. It has three sections, of which the first section designed, according to the women population of the Quetta city, was about demographic characteristics. The second section assessed the knowledge of the postmenopausal syndrome and the third section assessed the source of knowledge about the postmenopausal syndrome.

\section{Data Collection}

The primary source of data was face-to-face questioning. Most of the data were collected by a researcher who went to different areas of the Quetta city in a specified period of time. Some questionnaires were distributed along with a consent form, among women aged above 30 years in different areas of the Quetta city. The questionnaires were collected after 1 day by the researcher. The questionnaires were filled by the researcher itself for those women having no education.

\section{Data Analysis}

The data collected were verified and analyzed statistically using the IBM statistical software package (SPSS) for social science software, version 20. Descriptive statistics were used to demonstrate the characteristics of the study population. Categorical data are measured by frequency and percentage in which the variables are continuously expressed as a mean \pm standard deviation. Inferential statistics (Kruskal-Wallis tests, $p<0.05$ ) were used to assess the significance of study variables.

Multiple responses were applied for evaluating which of the source of information was highly used for attaining knowledge.

\section{Ethical Considerations}

The study was conducted under the guidance of the Pakistan National Bioethics Law and further research has been approved by a faculty of pharmacy of the University of Balochistan. According to the standard, a written agreement form was obtained from the research participants before data collection. Women are assured of the confidentiality of their answers and their right to leave the study at any time.

\section{Results}

\section{Demographic Characteristics}

The demographic characteristics of respondents are displayed in Table 1. The mean age of the participants was $38.06 \pm 6.194$ years. The largest group of women (194 (47.2\%)) fell within the age group of 31-35 years and the least number of respondents (4 (1.0\%)) were in the age group of 56-60 years. Most of the respondents were married (286 (69.6\%)), single (115 (28.0\%)), and widowed (10 (2.4\%)). Most of the respondents were Baloch 231 (56.2\%), Pathan 91 (22.1\%), Punjabi 62 (15.1\%), and others 16 (3.9\%); a the least number of respondents were Sindhi $11(2.7 \%)$. The qualification of most respondents was master's 168 (40.9\%), bachelor's 104 (25.3\%), and then participants with no education 62 (15.1\%). The frequency and percentage of the respondents with matric and inter qualification were same (i.e., 31 (7.5\%)). Totally, 12 (2.9\%) respondents were with middle education and the least number of respondents were with primary education $3(0.7 \%)$.

\section{Responses of the Women towards the Postmenopausal Syndrome}

Table 2 describes the responses of the respondent women towards the postmenopausal syndrome. Knowledge and awareness were assessed by questions focusing on etiology, sign and symptoms, diagnosis, treatment, management, and its complications. Each question was scored as "yes," "no," or "don't know".

All respondents $(411(100 \%))$ have heard about the postmenopausal syndrome. Most respondents (150 (36.5\%)) know about menopause in the absence of a menstrual period for 12 months after the reproductive age. Most of the respondents (302 $(73.5 \%))$ were aware of the age of menopause. Most respondents (231 (56.2\%)) had knowledge about premature menopause. Most women (332 (80.8\%)) know that the postmenopausal syndrome varies from women to women. Majority of the respondents know 
Table 1: Demographic characteristics of respondents

\begin{tabular}{|c|c|c|}
\hline Description & Frequency & Percentage \\
\hline \multicolumn{3}{|l|}{ Age group } \\
\hline 31-35 years & 194 & 47.2 \\
\hline $36-40$ years & 107 & 26.0 \\
\hline $41-45$ years & 57 & 13.9 \\
\hline $46-50$ years & 35 & 8.5 \\
\hline $51-55$ years & 14 & 3.4 \\
\hline $56-60$ years & 4 & 1.0 \\
\hline \multicolumn{3}{|l|}{ Marital status } \\
\hline Married & 286 & 69.6 \\
\hline Single & 115 & 28.0 \\
\hline Widowed & 10 & 2.4 \\
\hline \multicolumn{3}{|l|}{ Ethnicity } \\
\hline Baloch & 231 & 56.2 \\
\hline Punjabi & 62 & 15.1 \\
\hline Pathan & 91 & 22.1 \\
\hline Sindhi & 11 & 2.7 \\
\hline Others & 16 & 3.9 \\
\hline \multicolumn{3}{|l|}{ Qualification } \\
\hline Primary & 3 & 0.7 \\
\hline Middle & 12 & 2.9 \\
\hline Matric & 31 & 7.5 \\
\hline Inter & 31 & 7.5 \\
\hline Bachelors & 104 & 25.3 \\
\hline Masters & 168 & 40.9 \\
\hline None & 62 & 15.1 \\
\hline
\end{tabular}

the causes of the postmenopausal syndrome (PMS): a decrease in reproductive hormones-256 (62.3\%), removal of ovaries by surgery or chemotherapy-194 (47.2\%), and stress-275 (66.9\%). Majority of the respondents were aware of most signs and symptoms of the postmenopausal syndrome. These sign and symptoms are mental and physical changes (328 (79.8\%)), urinary disorder (213 (51.8\%)), anxiety, depression, mood swings and nervousness (261 (63.5\%)), weight gain (278 (67.6\%)), and insomnia (188 (45.7\%)). Most respondents did not know about some symptoms of the postmenopausal syndrome: dry skin 203 (49.4\%), vaginal dryness, itching and vaginal discharge 210 (51.1\%), hot flashes 177 (43.1\%), and night sweats 174 (42.3\%). Most women (186 (45.3\%)) know about the blood test used for the diagnosis of the postmenopausal syndrome. A large number of respondents (180 (43.8\%)) did not know about the hormone replacement therapy used for the treatment of the postmenopausal syndrome. Most of the respondents (232 (56.4\%)) had knowledge about the herbal and natural remedies used to remove the symptoms of the postmenopausal syndrome. Most of the respondents (178 (43.3\%)) did not know about the antidepressants used to remove symptoms of the postmenopausal syndrome. Most women (212 (51.6\%)) know about the management of menopause by a regular exercise and a healthy diet. A majority of the women (280 (68.1\%)) were aware of the complications of menopause: osteoporosis and heart disease (Tables 3 and 4).

\section{Assessment of Knowledge Regarding the Postmenopausal Syndrome}

Scoring was done on the extracted data. Every answer was recorded as "yes," "no," or do not know". Each accurate reply carried one mark; a wrong answer or a "don't know" response carried 0 marks. A total

Table 2: Responses of the women toward the postmenopausal syndrome

\begin{tabular}{|c|c|c|c|}
\hline Questions & Yes & No & Do not know \\
\hline Have you heard about the postmenopausal syndrome (PMS)? & $411(100 \%)$ & 0 & 0 \\
\hline Does menopause means the absence of menstrual period for 12 months after the reproductive age? & $150(36.5 \%)$ & $138(33.6 \%)$ & $123(29.9 \%)$ \\
\hline Does menopause typically occur between 45 years and 65 years of age? & $302(73.5 \%)$ & $45(10.9 \%)$ & $64(15.6 \%)$ \\
\hline Is it true that in some women, it may occur at an earlier age (less than 40 years)? & $231(56.2 \%)$ & $100(24.3 \%)$ & $80(19.5 \%)$ \\
\hline Does decrease in reproductive hormones cause the postmenopausal syndrome? & $256(62.3 \%)$ & $41(10.0 \%)$ & $114(27.7 \%)$ \\
\hline Can the removal of both ovaries by surgery or chemotherapy cause the postmenopausal syndrome? & $194(47.2 \%)$ & $63(15.3 \%)$ & $154(37.5)$ \\
\hline Can stress cause the postmenopausal syndrome? & $275(66.9 \%)$ & $51(12.4 \%)$ & $85(20.7 \%)$ \\
\hline Does the postmenopausal syndrome vary from women to women? & $332(80.8 \%)$ & $42(10.2 \%)$ & $37(9.0 \%)$ \\
\hline Does the postmenopausal syndrome lead to mental and physical changes? & $328(79.8 \%)$ & $47(11.4 \%)$ & $36(8.8 \%)$ \\
\hline Do most women suffer from urinary disorder during the postmenopausal syndrome? & $213(51.8 \%)$ & $50(12.2 \%)$ & $148(36.0 \%)$ \\
\hline Are anxiety, depression, mood swings, and nervousness are signs of the postmenopausal syndrome? & $261(63.5 \%)$ & $45(10.9 \%)$ & $105(25.5 \%)$ \\
\hline Does postmenopausal syndrome lead to a weight gain? & $278(67.6 \%)$ & $61(14.8 \%)$ & $72(17.5 \%)$ \\
\hline Is dry skin a symptom of postmenopausal syndrome? & $144(35.0 \%)$ & $64(15.6 \%)$ & $203(49.4 \%)$ \\
\hline Are vaginal dryness, itching, and vaginal discharge the symptoms of the postmenopausal syndrome? & $149(36.3 \%)$ & $52(12.7 \%)$ & $210(51.1 \%)$ \\
\hline Is insomnia a symptom of the postmenopausal syndrome? & $188(45.7 \%)$ & $80(19.5 \%)$ & $143(34.8 \%)$ \\
\hline Are hot flashes a symptom of the postmenopausal syndrome? & $158(38.4 \%)$ & $76(18.5 \%)$ & $177(43.1 \%)$ \\
\hline Do night sweats occur in the postmenopausal syndrome? & $155(37.7 \%)$ & $82(20.0 \%)$ & $174(42.3 \%)$ \\
\hline Does the postmenopausal syndrome is diagnosed by a blood test to check the levels of hormones? & $186(45.3 \%)$ & $50(12.2 \%)$ & $175(42.6 \%)$ \\
\hline Is the hormone replacement therapy used for the treatment of the postmenopausal syndrome? & $160(38.9 \%)$ & $71(17.3 \%)$ & $180(43.8 \%)$ \\
\hline Can herbal and natural remedies be used to remove the symptoms of the postmenopausal syndrome? & $232(56.4 \%)$ & $75(18.2 \%)$ & $104(25.3 \%)$ \\
\hline Can a low-dose antidepressant decrease menopausal hot flashes? & $163(39.7 \%)$ & $70(17.0 \%)$ & $178(43.3 \%)$ \\
\hline Do healthy diet and regular exercise minimize the symptoms of menopause? & $212(51.6 \%)$ & $71(17.3 \%)$ & $128(31.1 \%)$ \\
\hline Is it true that postmenopausal women are at an increased risk of osteoporosis and heart disease? & $280(68.1 \%)$ & $33(8.0 \%)$ & $98(23.8 \%)$ \\
\hline
\end{tabular}


Knowledge Regarding Postmenopausal Syndrome in Quetta, Pakistan

Table 3: Overall knowledge of respondents

\begin{tabular}{lll}
\hline Knowledge & Frequency & Percentage \\
\hline Poor knowledge & 193 & 47.0 \\
Adequate knowledge & 218 & 53.0 \\
\hline
\end{tabular}

Poor knowledge source $<13$

Adequate knowledge $\geq 13$

Table 4: Source of knowledge

\begin{tabular}{lcl}
\hline Source & Frequency & Percentage \\
\hline Internet & 144 & 35.0 \\
Healthcare professionals & 67 & 16.3 \\
Newspaper/magazine & 106 & 25.8 \\
Family & 140 & 34.1 \\
Friends & 136 & 33.1 \\
Relatives & 134 & 32.6 \\
Others & 44 & 10.7 \\
\hline
\end{tabular}

of 23 questions were included in the questionnaire. This made a $0-23$ range of score. A cutoff level is created on 13. A cutoff level of $<13$ was measured as poor knowledge, while $>12$ was regarded as adequate knowledge. Mean of the total knowledge score was $12.77 \pm 3.910$. Of the 411 women, 218 (53.0\%) have adequate knowledge and 193 (47.0\%) have poor knowledge.

\section{Source of Information}

Most of the participants mentioned from where (the origin) they learned about the postmenopausal syndrome, and most of the respondents mentioned more than one source. The internet is the most popular information source (144 (35.0\%)) followed by family $(140(34.1 \%))$, friends $(136(33.1 \%))$, and relatives $(134(32.6 \%))$. The source of knowledge from newspaper/magazine was 106 (25.8\%) and that from healthcare professionals was 67 (16.3\%); others mentioned by the participants were 44 (10.7\%).

\section{Assessment of Demographics with Knowledge Score}

Mean score is shown in Table 5. A comparison of the mean score with demographics among women population showed that there is no statistically significant difference found among age $(p=0.115)$, marital status ( $p=0.199)$, ethnicity $(p=0.370)$, and qualification $(p=0.654)$.

\section{Discussion}

Menopause is considered as a natural process that all women have to undergo at a certain point in their lives. With the increase in the elderly population having menopause symptoms and its long-term consequences, the need for solving this problem has gained the attention of the medical fields. Different studies showed that knowledge and attitudes regarding menopause are different across regions and countries according to their social and cultural factors. ${ }^{8}$

The overall knowledge of the present study was good. The same results were seen in a study conducted in Abu Dhabi and Sharjah. Several other studies had also shown that awareness and knowledge about menopause and HRT are good among women with higher education. Knowledge is also good among workers with professional occupations. These women will more probably go to a physician for menopause symptoms, as their jobs need
Table 5: Comparison of the mean score with demographics

\begin{tabular}{|c|c|c|c|c|}
\hline Character & Frequency & Mean & $S D$ & $p$ value \\
\hline \multicolumn{5}{|c|}{ Age groups (years) } \\
\hline $31-35$ years & 194 & 12.35 & 3.767 & 0.115 \\
\hline $36-40$ years & 107 & 13.31 & 4.299 & \\
\hline $41-45$ years & 57 & 12.67 & 4.063 & \\
\hline $46-50$ years & 35 & 12.57 & 2.758 & \\
\hline $51-55$ years & 14 & 14.93 & 3.931 & \\
\hline $56-60$ years & 4 & 14.25 & 3.862 & \\
\hline \multicolumn{5}{|l|}{ Marital status } \\
\hline Married & 286 & 12.95 & 3.805 & 0.199 \\
\hline Unmarried & 115 & 12.27 & 4.260 & \\
\hline Widowed & 10 & 13.30 & 1.889 & \\
\hline \multicolumn{5}{|l|}{ Ethnicity } \\
\hline Baloch & 231 & 12.53 & 3.724 & 0.370 \\
\hline Punjabi & 62 & 13.40 & 4.310 & \\
\hline Pathan & 91 & 13.08 & 3.928 & \\
\hline Sindhi & 11 & 13.18 & 3.371 & \\
\hline Others & 16 & 11.69 & 5.003 & \\
\hline \multicolumn{5}{|l|}{ Qualification } \\
\hline Primary & 3 & 15.33 & 4.163 & 0.654 \\
\hline Middle & 12 & 11.67 & 4.942 & \\
\hline Matric & 31 & 12.58 & 3.956 & \\
\hline Inter & 31 & 13.84 & 4.140 & \\
\hline Bachelors & 104 & 12.45 & 3.566 & \\
\hline Masters & 168 & 12.65 & 3.777 & \\
\hline Others & 62 & 13.26 & 4.417 & \\
\hline
\end{tabular}

them to be alert and active all the time, without the limitations of the menopause symptoms. ${ }^{8}$

The same study was conducted and the results were the same. The reason behind good knowledge was their high level of education and most respondents used the internet as the primary source of knowledge (where the information is updated every day) and have also gained information from family, friends, and relatives; nowadays, most women visit doctors or physicians for a regular checkup, who guide them about their health, and they were in touch with newspaper and magazines, which help them to be armed with the knowledge as to how to manage the symptoms of menopause.

Several other studies show that knowledge about menopause and HRT and attitudes towards HRT are significantly affected by the econimc class of women. A study conducted in the city of Al-Ain, UAE showed similar results. The participants in the study have poor information about menopause (67\%) and HRT (73\%). The deprived awareness of the members was due to a low level of education. In this study, this may be due to the fact that problems related to sexual and reproductive health are not officially taught nor were they spoken by doctors. ${ }^{9}$ This study showed that doctors, regardless of patient contact, did not discuss menopausal issues with $87 \%$ of participants. Women collected information primarily from family, friends, the media, and through their experience. The majority of women (76\%) who lose menopause are the natural stages of a woman's life. This result is similar to the results obtained in Bahrain and Italy in 2009, indicating a lack of knowledge about menopause related to low levels of education. In addition, our study found that "heat" was the most common symptom (in $63 \%$ of women 
with $n=80$ ). A previous study in the UAE found that $45 \%$ of the population reported "hot flashes". 9

In the study discussed above, the respondents show a positive response regarding the postmenopausal syndrome. Although the overall knowledge of the respondents was good, there are some things that need to be explained to the women that are they were unaware of: some symptoms of the postmenopausal syndrome. These symptoms are dry skin (203 (49.9\%)), vaginal itching, vaginal discharge (210 (51.1\%)), hot flashes (177 (43.1\%)), and night sweats (174 (42.3\%)). Majority of the respondents 180 (43.8\%) had no knowledge about hormone replacement therapy (HRT) and most of them did not know about SSRIs (low dose antidepressants). To increase awareness about the postmenopausal syndrome among women, different teaching programs and seminars should be arranged that help them to manage the symptoms and improve their quality of life (QoL). A study was conducted in Korean middleaged women, which showed that age can affect the knowledge level of women regarding menopause. The differences are found in the knowledge about menopause by age, level of education, occupation, and spouse. ${ }^{10}$ The knowledge and attitude of menopause in general women with education and young women have more knowledge about menopause. The average knowledge about menopause was 9.0 of a perfect score of 17.0, indicating a significant difference in educational achievement. ${ }^{10}$

Women with little knowledge of menopause should be encouraged to participate in health management activities to have better knowledge and care. On knowledge about menopause by level of education, women with lower education tend to be more interested in menopause. These findings show results similar to those of the previous studies. Therefore, knowledge about menopause is very important to improve the management of menopause. ${ }^{10}$ The results show that a broader database is needed to develop education programs appropriate for menopause in order to increase the level of knowledge about menopause in middle-aged women. Uneducated women with a good knowledge of menopause and postmenopausal women were also positively associated with the premenopausal women in this study. ${ }^{10}$ In this study, the knowledge of respondents (218 (53.0\%)) was good regarding the postmenopausal syndrome, but still there are some points that need to be explained about the postmenopausal symptoms and management. Majority of the respondents in this study were married (286 (69.6\%)) and were with a high level of education (168 (40.9\%)), which indicates a positive response towards the postmenopausal syndrome. The reason behind good knowledge must be that they have gained information from the internet, books, newspaper/magazine, and from other sources such as seminars. Some respondents were with a poor knowledge regarding the postmenopausal syndrome. According to a study conducted in the State University of New York College at Cortland, most of the women were satisfied at some level about the knowledge they have gained regarding menopause. ${ }^{11}$ This result is the same with that obtained in the study by Utian and Schiff (1994). ${ }^{12}$ The results have proved the third hypothesis as correct, which was that the women are satisfied with the overall knowledge or information they have about menopause. ${ }^{13}$ The same results were seen in this study regarding the postmenopausal syndrome. Most women knew about the postmenopausal syndrome and causes, symptoms, diagnosis, and treatment related to it. Most of the women had a master's degree and used the internet and newspaper and other sources to gain information regarding the postmenopausal syndrome. Statistical significance was more than $p>0.05$ and was independent of the demographics (i.e., age, marital status, ethnicity, and qualification), which means the knowledge has no effect on age, marital status, ethnicity, and qualification.

\section{Conclusion}

The purpose of this study was to assess the knowledge in women regarding the postmenopausal syndrome, its causes, symptoms, diagnosis, treatment, and complications. This study found that knowledge among women regarding the postmenopausal syndrome is important for improving the QoL in women and for managing the symptoms of the postmenopausal syndrome. The study respondents showed an adequate level of knowledge about the postmenopausal syndrome; however, there were areas of knowledge that need improvement by health education. Healthcare professionals should provide all the necessary information to women about the postmenopausal syndrome. The ratio of poor knowledge can be improved by raising awareness and increasing the educational level of women.

\section{Recommendations}

Education should be given to women at different levels. Seminars and other educational programs need to be conducted for the promotion of information regarding the postmenopausal syndrome. Knowledge and awareness campaigns need to increase the awareness of postmenopausal syndrome. Public healthcare systems should organize resources and take measures to improve women's awareness and knowledge about menopause-related changes. A recommendation for physicians would be to provide more information about menopausal symptoms and also therapies to alleviate these symptoms.

\section{References}

1. Agarwal PKDaM. Postmenopausal syndrome. 2015 [cited (2016) (06/10)]; Available from: https://www.ncbi.nlm.nih.gov/pmc/articles/ PMC4539866/.

2. Sussman M, Trocio J, et al. Prevalence of menopausal symptoms among mid-life women: findings from electronic medical records. BMC Womens Health 2015;15:58. DOI: 10.1186/s12905-015-0217-y.

3. Dutta DR. A Population Based Study on the Menopausal Symptoms in a Rural Area of Tamil Nadu, India; 2012.

4. Nordqvist C. Menopause: Symptoms, Causes and Treatments. 2015.

5. Melissa Conrad Stöppler M. Menopause; 2016 [cited (2016) (07/10)]; Available from:http://www.medicinenet.com/menopause/page10.htm.

6. Nusrat N. Knowledge, Attitude and Experience of Menopause 2008.

7. Badran IG. Knowledge, attitude and practice the three pillars of excellence and wisdom: a place in the medical profession; 1995.

8. Ibrahim OM. Knowledge, Attitude, and Prevalence of Use of Hormone Replacement Therapy Among Women in United Arab Emirates; 2016.

9. Hamid S, Al-Ghufli FR, et al. Women's knowledge, attitude and practice towards menopause and hormone replacement therapy: a facility based study in Al-Ain, United Arab Emirates. J Ayub Med Coll Abbottabad 2014;26(4):448-454.

10. Kwak EK, Park HS, et al. Menopause knowledge, attitude, symptom and management among midlife employed women. J Menopausal Med 2014;20(3):118-125. DOI: 10.6118/jmm.2014.20.3.118.

11. Beneria L, Santiago LE. The impact of industrial relocation on displaced workers: A case study of Cortland, New York. Econ Dev Q 2001;15(1):78-89. DOI: 10.1177/089124240101500107.

12. Utian WH, Schiff I. NAMS-Gallup survey on women's knowledge, information sources, and attitudes to menopause and hormone replaceent therapy. Menopause 1994;1(1):39-48. DOI: 10.1097/00042192-199400110-00007.

13. Carter JC. The Assessment of Women's Knowledge of Menopause; 2009. 